\title{
Perseverance is innovation: the journey to successful tobacco tax reform
}

\author{
Jeffrey Drope (ㄷ, , ${ }^{1}$ Erika Siu 지, ${ }^{2}$ Frank J Chaloupka (구 ${ }^{2}$
}

\begin{abstract}
- Additional supplemental material is published online only. To view, please visit the journal online (http://dx.doi. org/10.1136/tobaccocontrol2021-057088).
\end{abstract}

${ }^{1}$ Health Policy and

Administration, School of Public Health, University of Illinois at Chicago, Chicago, IL, USA ${ }^{2}$ Institute for Health Research and Policy, University of Illinois at Chicago, Chicago, Illinois, USA

\section{Correspondence to}

Dr Jeffrey Drope, Health Policy and Administration, School of Public Health, University of Illinois at Chicago, Chicago, IL, USA; jdrope@uic.edu

\section{Linked}

http://dx.doi.org/10.1136/ tobaccocontrol-2021-056554

Check for updates

(C) Author(s) (or their employer(s)) 2022. No commercial re-use. See rights and permissions. Published by BMJ.

To cite: Drope J, Siu E, Chaloupka FJ. Tob Control 2022;31:241-242.
The tobacco control community consistently describes tobacco taxation in two ways: it is the most effective intervention and the least implemented. ${ }^{1}$ The scholarship on tax's effectiveness for decreasing consumption and increasing tax revenues has depth and breadth. ${ }^{2}$ In contrast, implementation research - that is, how, when and why governments change their tax structures and/or rates- is poor. Even the most comprehensive resource on tobacco economics, the National Cancer Institute Monograph 21 (with WHO), does not dedicate a section or sub-section to implementation. ${ }^{2}$ In this issue, Scollo and Branston offer a creative and plausible pathway to push tobacco taxation in countriesalmost always, high-income-already performing well on tax. ${ }^{3}$ In fact, the greatest challenges with tax implementation are in low-tax countries, almost always low-income or middle-income countries (LMICs), which are also the ones with the most potential public health gain because that is where most smokers live. Moreover, LMICs are likely to benefit most from new tax revenues that can help to pay for the increasing burdens on health systems exacerbated by the COVID-19 pandemic and postpandemic recovery efforts.

The second edition of the Tobacconomics Cigarette Tax Scorecard reports that globally, most countries are doing poorly on the key facets of implementation: optimising tax structure; raising prices; increasing the tax share of price and decreasing affordability. ${ }^{4}$ As figure 1 suggests, the global average overall and component scores are low and increased only incrementally from 2014 to 2020 (see online supplemental appendix for scoring rubrics). In other words, prices and tax shares of price are too low, affordability is not changing in enough countries and tax structures are still suboptimal in most countries. The main plausible explanation is undoubtedly the tobacco industry's success at thwarting tobacco tax reforms. The industry correctly recognises tax as an existential threat, which is reflected in their herculean and comprehensive efforts to undermine tax reform efforts.

Yet, little is known about the policy 'supply' side: governments making tax policy. Some governments appear modestly interested in the idea of raising tobacco excise taxes, but with less than $15 \%$ of the world population living in countries meeting WHO's minimum benchmark that tax share of price be at least $75 \%$, it suggests that interest and engagement remain tepid. As figure 2 suggests, tobacco tax progress is inversely related to country income. For governments, it is partly an ongoing calculation of whether the projected revenue increases and/or public health benefits are worth the political headaches from relentless industry pressure and/or some genuine challenges that sometimes arise like small increases in illicit trade. Fortunately, several recent promising reforms scattered around the globe give cause for hope. For example, the Gulf Cooperation Council countries coordinated to abandon an import duty-only regime for a uniform ad valorem tax and Kyrgyzstan simplified a complicated tiered structure. In all these countries, prices went up and tobacco products became demonstrably less affordable.

There are some overarching components of successful implementation worth noting. Most are not sufficient on their own, and under some circumstances, not all are necessary.

Arguably strong political will is the most crucial condition. It is always necessary, but never sufficient. There are no known examples of countries where those who wielded the real political power to reform tobacco taxes opposed them and then the taxes were somehow raised anyway. Engendering this will is an ongoing challenge.

Compelling evidence is almost always necessary but is never sufficient for policy success. Although there is a strong research foundation across varied contexts, governments very often want country-specific studies, and it is challenging to convince these governments that the overall relationships are consistent. This requires research capacity across regions or even countries to quickly generate these outputs and this capacity is frequently lacking.

Technical capacity of the tax authorities is always necessary but is never sufficient for tax reform. Implementing and then enforcing a tax regime requires a tax authority that understands the mechanics of different options-for example, why a uniform specific excise tax with regular increases to account for inflation and income growth is easiest to administer and most likely to reap both the public health and revenue benefits-and has the requisite ability to implement the reforms. Most of the time, it is possible to build this capacity in-country, but it takes effort, resources and commitment from within and, often, from external sponsors.

Civil society activism is often necessary to build and promote the political will highlighted previously, but it is never sufficient. In countries with a vibrant and coordinated civil society and where their actions have genuine effect, their role has proven to be very important in tobacco tax reform. In the Philippines' landmark 2013 tobacco tax reform, civil society coalitions helped to propel the 


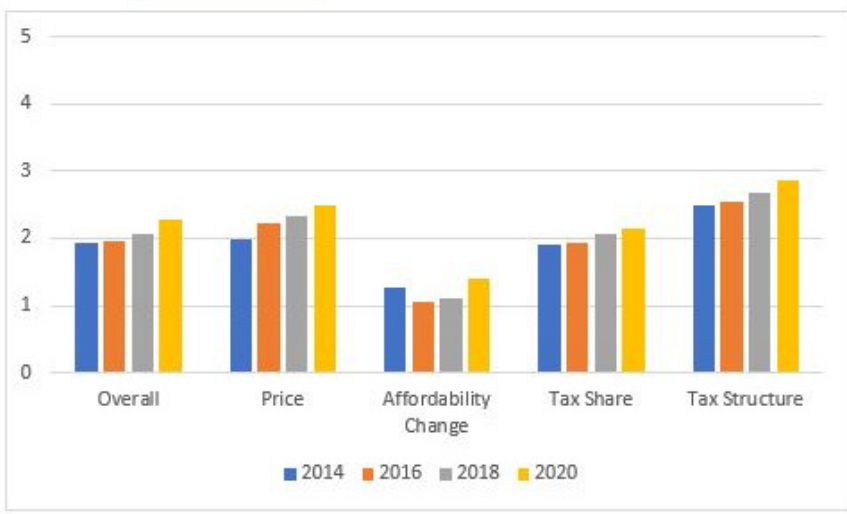

Figure 1 Tobacconomics Cigarette Tax Scorecard results, 2014-2020.

presidentially supported reform through an initially reluctant legislature. $^{5}$

Conceptually, these four components interact somewhat multiplicatively, and if any of them exist at very low levels (or worse, do not exist), the likelihood of success diminishes markedly. This dynamic reinforces that in most circumstances, efforts to maximise each component are necessary.

The question remains: where does the tobacco control community go from here to improve implementation? First, it is critical to recognise that tobacco taxation is going to be an ongoing effort. This is likely to be unpopular even with many proponents because 'success' will feel illusory. However, unlike many other interventions that rarely face reversals (eg, smoke-free, packaging regulations, etc), the tobacco industry and its allies will challenge taxation at least every budget cycle. Although not foolproof, one approach that can help mitigate this is to push for multi-year tax reforms that are designed to commit governments to effective approaches.

Many governments' goal of improving tax administration is consistent with the goal of accelerating tobacco taxation. Accordingly, where possible, pairing tobacco tax reform with programmes to improve tax administration is a potentially fruitful strategy. Moreover, such efforts are congruent with those of multilateral financial organisations like the World Bank and the International Monetary Fund, and they can be powerful allies for reform.

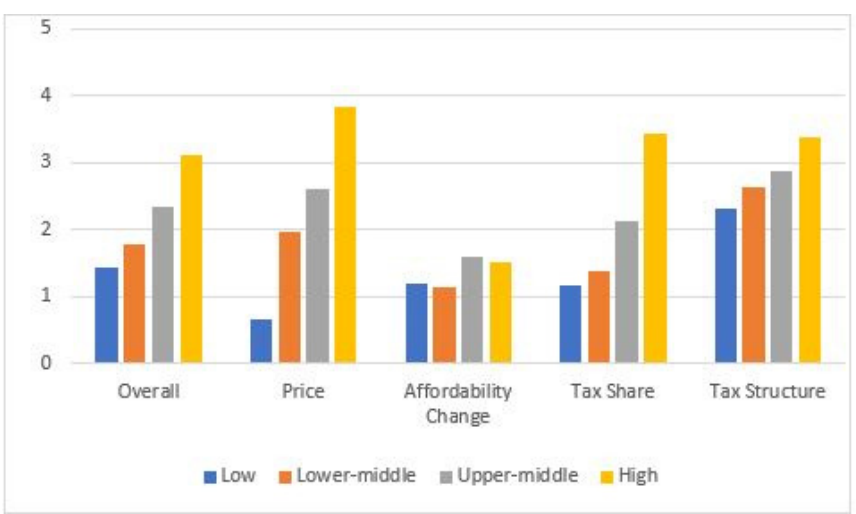

Figure 2 Tobacconomics Cigarette Tax Scorecard results by World Bank country income group, 2020.
Remarkably, the argument that governments should increase tobacco taxes because of the enormous and well-documented costs of tobacco use, both direct healthcare costs and productivity losses from premature death and increased morbidity, ${ }^{6}$ fails to resonate with some, even many, governments. This may be because those losses are reversed much more slowly than politicians' electoral cycles. Considering also finance ministries' concerns about limited revenue returns, it is important to reinforce the poignant and perhaps more emotional health argument: tobacco taxes save lives. This approach is also useful for engaging a broader coalition of stakeholders who might become strong proponents of reform. Another related strategy is to consider how to allocate new tax revenues. Whereas many finance ministries are wary about the inflexible nature of earmarking, connecting new revenues more loosely to programmes ('soft' earmarks), especially ones that promote broad societal wellbeing, are popular with the public and elected officials, whose support is paramount.

The tobacco control community must also re-double efforts to raise awareness about the efficacy of tobacco taxes across key facets: better health, increased revenues and lower costs, among others. This will require ongoing engagement motivated by key sympathetic stakeholders-so-called 'champions'-including civil society and relevant government agencies. Innovation is a compelling goal to push implementation, but such an emphasis might be misplaced, and we should instead focus on the necessary tasks that we know generate success.

\section{Twitter Erika Siu @erikadayle}

Contributors Based on the authors' ongoing work supporting tobacco taxation reform globally, JD wrote the first draft. ES and FJC provided inputs on the draft. All authors contributed to and agreed upon the final version of the manuscript.

Funding This study was partly based on research funded by Fogarty International Center (R01 TW010898); Bloomberg Philanthropies; and the National Cancer Institute (R01 TW010898). It represents the views of the authors and not necessarily those of the funders.

Competing interests None declared.

Patient consent for publication Not applicable.

Ethics approval This study does not involve human participants.

Provenance and peer review Commissioned; externally peer reviewed.

ORCID iDs

Jeffrey Drope http://orcid.org/0000-0003-0147-9722

Erika Siu http://orcid.org/0000-0002-1274-2058

Frank J Chaloupka http://orcid.org/0000-0003-4048-4065

\section{REFERENCES}

1 World Health Organization. WHO technical manual on tobacco tax policy and administration. Geneva: World Health Organization. License: CC BY-NC-SA 3.0 IGO, 2021.

2 U.S. National Cancer Institute and World Health Organization. The economics of tobacco and tobacco control. National Cancer Institute Tobacco Control Monograph 21. NIH Publication No. 16-CA-8029A. Bethesda, MD: U.S. Department of Health and Human Services, National Institutes of Health, National Cancer Institute; and Geneva, CH: World Health Organization, 2016.

3 Scollo M, Branston R. Where to next for countries with high tobacco taxes? The potential for greater control of tobacco pricing through licensing regulation. Tob Control 2022;31:235-40.

4 Chaloupka F, Drope J, Siu E. Tobacconomics Cigarette Tax Scorecard. Second edition. Chicago, IL: Health Policy Center, Institute for Health Research and Policy, University of Illinois Chicago, 2021. www.tobacconomics.org/cigarette-tax-scorecard

5 Kaiser K, Bredenkamp C, Iglesias R. Sin tax reform in the Philippines: transforming public finance, health, and governance for more inclusive development. Directions in development - countries and regions. Washington, DC: World Bank, 2016. https:// openknowledge.worldbank.org/handle/10986/24617

6 Goodchild M, Nargis N, Tursan d'Espaignet E. Global economic cost of smokingattributable diseases. Tob Control 2018;27:58-64. 